\title{
Cerebrotendinous Xanthomatosis, A Rare Metabolic Disease
}

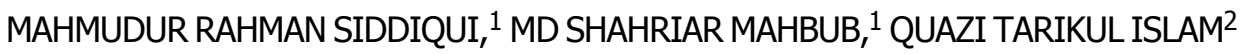

\begin{abstract}
:
Cerebrotendinous xanthomatosis (CTX) is a rare genetic lipid storage disease. CTX is characterised by childhood-onset cataract, adolescent to young adult-onset tendon xanthomas and adult-onset progressive neurological dysfunction (dementia, psychiatric disturbances, pyramidal and/or cerebellar signs and seizures). A 32-year-old male patient presented to us with the features of this rare genetic metabolic disorder.
\end{abstract}

Keyword: Cerebrotendinous xanthomatosis, tendon xanthoma, seizure, lipid storage disease.

\section{Introduction:}

Cerebrotendinous xanthomatosis (CTX) is a rare genetic metabolic disorder of cholesterol and bile acid metabolism that results in systemic and neurologic abnormalities. The patient develops multiple tendon xanthomas, cataract and neu-rological deficits (dementia, psychiatric disturbances, pyramidal and/or cerebellar signs and seizures). ${ }^{1,2}$ The disease was first described in 1937 by Van Bogaert and colleagues. ${ }^{3}$ More than 300 patients have been diagnosed worldwide, with an estimated prevalence of 1 case per 50,000 individuals in white populations. ${ }^{4}$ It can present at any age with no sex differentiation. Early diagnosis during childhood helps early treatment that prevents progression of disease.

\section{Case Report:}

A 32-year-old male patient presented with an illness that had started from his childhood with the development of multiple gradually enlarging painless skin swellings over knees, ankles, elbows and dorsum of the feet. He did not complete his primary education because of learning difficulties. For last 2 years he had been suffering in recurrent seizure. On examination, the patient's IQ was below average. There were multiple subcutaneous swellings of different size and shape over the extensor surfaces of the knees, ankles, elbows, left great toe and dorsum of the right foot. They were firm, nontender and fixed with underlying tendons. He also had bilateral cataract. The biochemical and haematological investigations, including the lipid proûle were normal. CT scan of the head showed generalized mild cortical atrophy. Histopathological examinations of the tissue from xenthoma revealed Birefringent lipid crystals are surrounded by giant cells. With all of these findings he was diagnosed as a case of very rare lipid storage disease called Cerebrotendinous xanthomatosis (CTX).
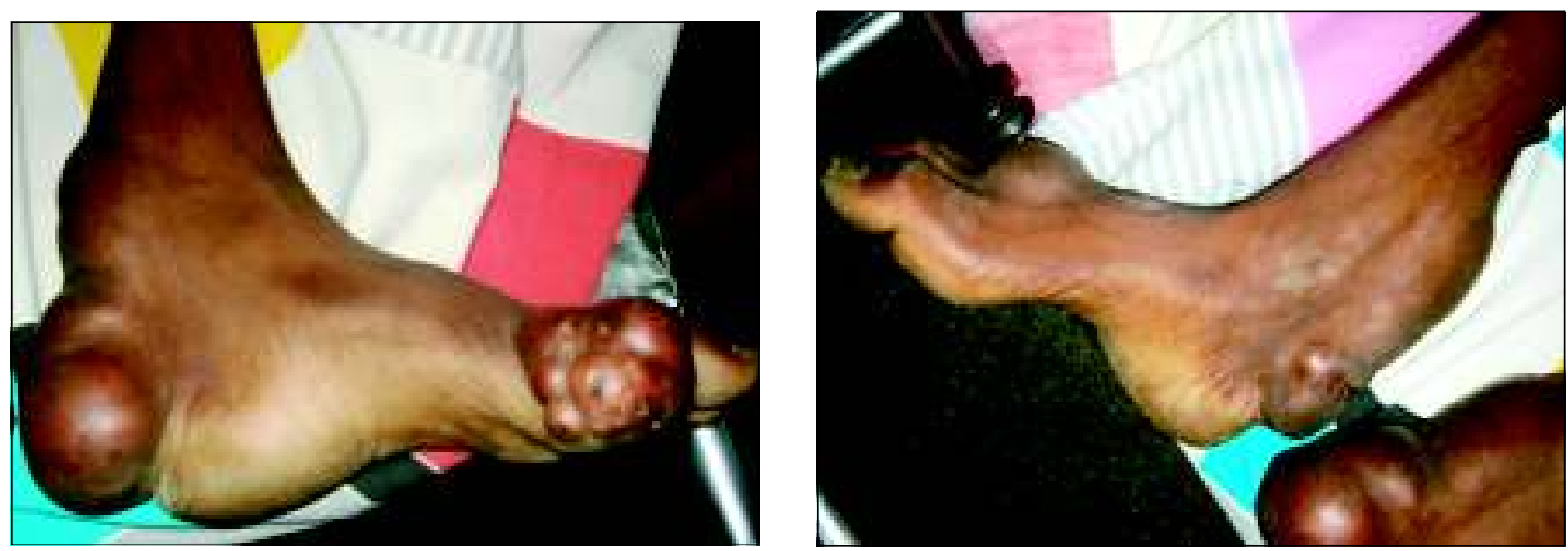

Fig-1: Xanthoma over both tendoachilles, left great toe, dorsum of right foot.

1. Consultant, Medicine, The Medical Center

2. FCPS Medicine P-II Course, DMCH.

3. Professor of Medicine, Department of Medicine, DMCH.

Correspondence: Dr. Mahmudur Rahman Siddiqui, DMCH. E-mail: dr.mahmud99@yahoo.com 



Fig-2: Xanthoma over both knees.

\section{Discussion:}

Cerebrotendinous xanthomatosis is a rare autosomal recessive lipid-storage disease caused by mutations in the sterol 27-hydroxylase gene. Deûciency of the enzyme 27hydroxylase causes an impairment of the metabolic pathway of bile acid synthesis from cholesterol, resulting in an excessive production of cholestanol, which then accumulates in many tissues (brain, tendon, muscle, blood vessels etc). The disease begins in infancy. Bilateral cataracts associated with chronic diarrhoea may be the earliest clinical manifestations. Xanthomata develop in the second and third decades of life. They are usually found on the Achilles tendon but may also be found on the patella, elbow, hand, and neck tendons. Signiûcant neurological impairment also occurs; this often includes mental retardation, seizures, dementia and pyramidal and/or extra pyramidal dysfunction and typically begins in the third decade of life but the clinical presentations may vary considerably. ${ }^{1,2,5}$

High plasma and tissue cholestanol concentration with normal-to-low plasma cholesterol concentration and decreased chenodeoxycholic acid can easily differentiate it from other xanthomatous diseases (Familial hypercholesterolaemia, Sitosterolemia). ${ }^{1,2}$ Bile acid production is reduced, although the activity of the rate-limiting enzyme of bile production is elevated. ${ }^{6} \mathrm{MRI}$ and CT scanning may revealed diffuse atrophy of the brain, as well as focal lesions (including demyelinating lesions and rarely, xanthomata) in the cerebellum, basal ganglia, and cerebrum. ${ }^{7}$ Histopathology can be done from affected tissue which usually revealed spindle-shaped lipid crystal clefts, fibrosis, hemosiderin deposition surrounded by giant cells with foamy cytoplasm. ${ }^{8}$

Long term treatment with chenodeoxycholic acid (CDCA) effective in decreasing cholestanol concentration and improving clinical features. ${ }^{1,9}$ If hypercholesterolemia is not controlled with CDCA treatment alone, 3-hydroxy-3methylglutaryl-CoA (HMG-CoA) reductase inhibitors may be added. ${ }^{9}$ This is a progressive and terminal disease if left untreated. Treated patients may have a normal lifespan.

\section{Conflict of Interest: None}

\section{References:}

1. Husseiny NME. Cerebrotendinous xanthomatosis associated with immune thrombocytopenia. BMJ Case Reports 2010; doi:10.1136/bcr.02.2010.2736.

2. Bhojwani RA, Khot R. Cerebrotendinous xanthomatosis: a rare genetic disorder. BMJ Case Reports 2011;doi:10.1136/ bcr.08.2011.4582.

3. Van Bogaert L, Scherer HJ, Epstein E. Une forme cerebrale de la cholesterinose generalisee [dissertation/master's thesis]. Paris: Masson et Cie. 1937.

4. Gallus GN, Dotti MT, Federico A. Clinical and molecular diagnosis of cerebrotendinous xanthomatosis with a review of the mutations in the CYP27A1 gene. Neurol Sci. Jun 2006;27(2):143-9.

5. Federico A, Dotti MT. Cerebrotendinous xanthomatosis . In: Vinken PJ, Bruyn GW, Moser HW, eds. Handbook of Clinical Neurology. Amsterdam : Elsevier Science 1996 ;66:599-613.

6. Salen G. Cholestanol deposition in cerebrotendinous xanthomatosis. A possible mechanism. Ann Intern Med 1971;75:843-51 .

7. De Stefano N, Dotti MT, Mortilla M, et al. Magnetic resonance imaging and spectroscopic changes in brains of patients with cerebrotendinous xanthomatosis. Brain. Jan 2001;124:121-31.

8. Federico A, Dotti MT, Volpi N. Muscle mitochondrial changes in cerebrotendinous xanthomatosis. Ann Neurol. Nov 1991;30(5):734-5.

9. Batta AK, Salen G, Tint GS. Hydrophilic 7 beta-hydroxy bile acids, lovastatin, and cholestyramine are ineffective in the treatment of cerebrotendinous xanthomatosis. Metabolism. May 2004;53(5):556-62. 